\title{
Syncopal Attack! - A Rare Complication after Whitacre Spinal Needle Insertion during Spinal Anaesthesia
}

\author{
Sanjot Ninave ${ }^{1}$, Aditya Rameshbabu Devalla ${ }^{2}$ \\ 1,2 Department of Anaesthesiology, Jawaharlal Nehru Medical College, Datta Meghe \\ Institute of Medical Sciences, Sawangi (Meghe), Wardha, Maharashtra, India.
}

\section{INTRODUCTION}

Fine gauze spinal needles are known to decrease the incidence of postdural puncture headache (PDPH) in patients undergoing spinal anaesthesia. We present a rare case of syncopal attack in a patient posted for caesarean section. A patient undergoing elective surgery with inadequate anxiolysis can have a rare chance of a syncopal attack. Hence, high level of suspicion and management of a vasovagal attack is vital. The most common mechanism of syncope is reflex mediated, which can be 'neurally' or 'vasovagally', and it characteristically develops in the sitting or upright position but may occur in supine position also. ${ }^{1,2}$ It is characterized by a rapid onset, brief duration, and with a spontaneous recovery. Anxious and apprehensive patients prior to any surgical or anaesthetic procedure can lead to a vasovagal syncope, especially in young females. ${ }^{3}$

Medline search did not reveal any case report regarding the vasovagal syncope just after spinal needle insertion in young females undergoing spinal anaesthesia. Spinal anaesthesia is the most common anaesthesia performed for lower segment caesarean section (LSCS). A case of syncopal attack with sequence of events, during the insertion of a $25 \mathrm{G}$ Whitacre spinal needle, in a parturient posted for emergency lower segment caesarean section, is discussed here.

\section{PRESENTATION OF CASE}

A 26-year-old primigravida (body weight $60 \mathrm{kgs}$, height $166 \mathrm{cms}$, ASA II) was taken up for emergency lower segment caesarean section in view of foetal bradycardia. Her pre-operative routine laboratory tests revealed normal complete blood counts and biochemical parameters. An informed consent was taken prior to administration of anaesthesia.

Intravenous access was secured with an $18 \mathrm{G}$ intravenous catheter and injection Ondansetron $4 \mathrm{mg}$ was given as an antiemetic. Monitors were connected to the patient for continuous monitoring of heart rate, electrocardiogram (ECG), noninvasive blood pressure (NIBP) and oxygen saturation (SpO2). The patient was preloaded with Ringer's lactate solution $15 \mathrm{ml} / \mathrm{kg}$. The patient was given a sitting position. During this whole procedure, the patient was a bit apprehensive and anxious. Vitals were heart rate (HR) - 110 / min, NIBP - 120 / 76 mmHg, and SpO2 $100 \%$.

Under all aseptic precautions, $25 \mathrm{G}$ Whitacre spinal needle [Figure 1] was inserted at L3 - L4 interspace and $2 \mathrm{ml}$ of $0.5 \%$ Bupivacaine $(\mathrm{H})$ administered. Soon after, the patient complained of light headedness and nausea, following which she collapsed within a few seconds over the assisting technician in front of her. The spinal needle was still present inside the patient's back at that moment. Withdrawal of the needle immediately met with a lot of resistance as it was bent inside the patient. With gentle pulling, we were able to extract the needle from the back of the patient, which was bent in a "U" shape [Figure 2].
Corresponding Author: Dr. Aditya Rameshbabu Devalla, 68, Tiwari Layout, Warud, Post: Sewagram, District: Wardha - 442102, Maharashtra, India.

E-mail: adimgims10@gmail.com

DOI: $10.14260 /$ jemds/2021/381

How to Cite This Article:

Ninave S, Devalla AR. Syncopal attack! - a rare complication after Whitacre spinal needle insertion during spinal anesthesia. J Evolution Med Dent Sci 2021;10(24):18451847, DOI: $10.14260 /$ jemds/2021/381

Submission 01-02-2021,

Peer Review 14-04-2021,

Acceptance 20-04-2021,

Published 14-06-2021.

Copyright (C) 2021 Sanjot Ninave et al. This is an open access article distributed under Creative Commons Attribution License [Attribution 4.0 International (CC BY 4.0)] 

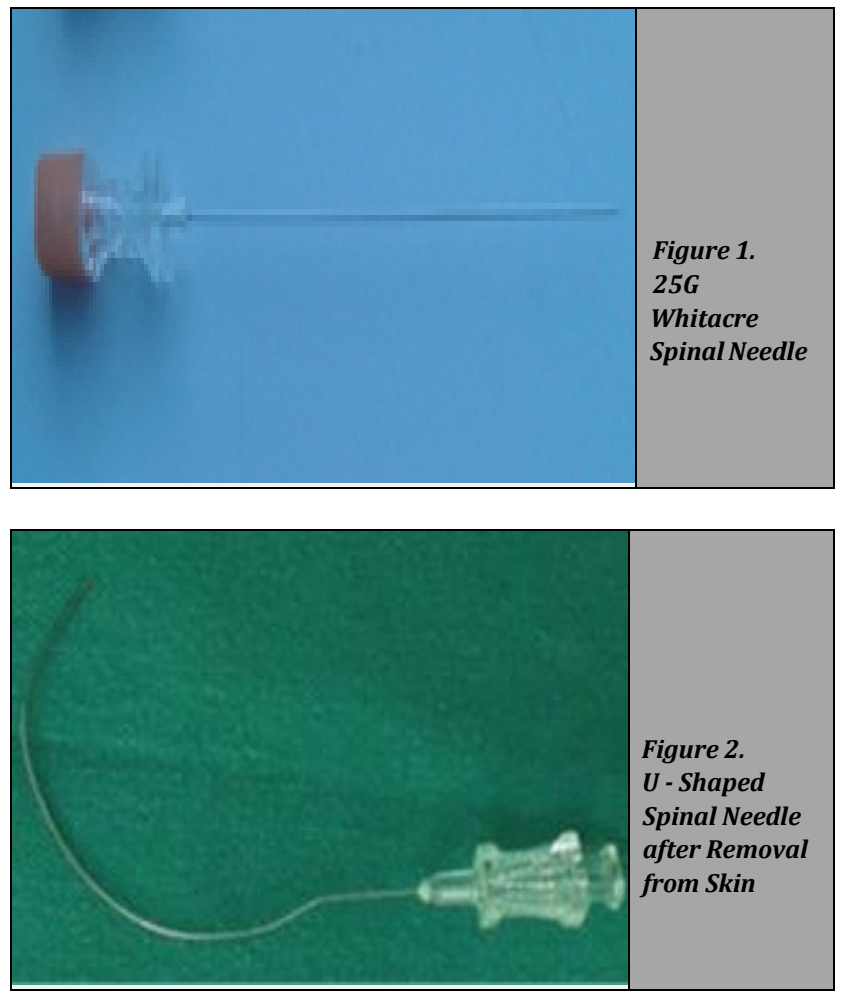

The patient was given supine position immediately and the vitals were HR - 40 / min, NIBP - 86 / 50 mmHg, and SpO2 $99 \%$ on room air. The patient became unresponsive with decreased muscle tone. Immediately atropine $0.6 \mathrm{mg}$ IV injection was given and as the patient was still spontaneously breathing, $100 \%$ oxygen was administered by Bains circuit. The patient was placed in a left lateral position and simultaneously jaw thrust was given. Blood was drawn for measuring blood sugar levels and arterial blood gas (ABG) analysis. After 1 minute of pharmacological resuscitation and oxygenation, the patient regained her consciousness. The vitals recorded were HR - 96 / min, NIBP - 104 / 70 mmHg, and $\mathrm{SpO} 2-100 \%$. Blood sugar was $84 \mathrm{mg} / \mathrm{dL}$ and $\mathrm{ABG}$ was within normal limit.

The LSCS was otherwise conducted uneventfully. At the end of surgery, she was shifted to postoperative care unit for further monitoring and observation.

\section{DISCUSSION}

The common causes of syncope are hypoglycaemia, ${ }^{4}$ hypoxia, ${ }^{5}$ seizures, ${ }^{6}$ electrolyte disturbances, ${ }^{7}$ cardiogenic abnormalities, 8 acute haemorrhage, intoxication, or vasovagal attack. In our case, the chance of hypoglycaemia, hypoxia, and electrolyte disturbances were excluded as blood sugar, ABG, and SpO2 were within the normal range. Local anaesthetic was not infiltrated before spinal needle insertion because we assumed to be successful in a single attempt. The prodromal symptoms shown during the insertion of needle suggested that it may be a case of vasovagal attack due to pain.

Vasovagal syncope is a reflex of the nervous system that causes bradycardia and dilatation of blood vessels (pooling of the blood) in the legs ${ }^{9}$ that leads to decreased cardiac output and cerebral perfusion. ${ }^{10}$ All these events lead to cerebral hypoxia and ultimately fainting episode occurs. It has 3 distinct phases - A prodromal phase, loss of consciousness, and a post syncopal phase. Emotional stress, trauma, pain, sight of blood, prolonged standing, etc. are usually precipitating factors for vasovagal syncope. In our case, the cause of vasovagal syncope might be fear of anticipated pain induced by introduction of spinal needle in an already apprehensive patient.

The prodrome is characterized by sweating, epigastric discomfort, extreme fatigue, weakness, yawning, nausea, dizziness, and vertigo and results from increased parasympathetic tone, and may last for seconds to several minutes.

Lying down or removing the stimulus may abort the syncopal episode. The post-syncopal phase may last hours or, rarely, days and may include protracted confusion, disorientation, nausea, dizziness, and a general sense of poor health. ${ }^{11} \mathrm{~A}$ prolonged post-syncopal phase may be associated with causes more serious than vasovagal stimulation and should prompt a more extensive evaluation.

\section{CONCLUSIONS}

An anxious patient, especially a female can develop syncopal attack due to a painful stimulus such as insertion of spinal needle. Hence, proper counselling along with early identification and management of a vasovagal attack is crucial.

Financial or other competing interests: None.

Disclosure forms provided by the authors are available with the full text of this article at jemds.com.

\section{REFERENCES}

[1] Brignole M, Alboni P, Benditt D, et al. Task force on syncope, European Society of Cardiology. Part 1. The initial evaluation of patients with syncope. Europace 2001;3(4):253-60.

[2] Van Lieshout JJ, Wieling W, Karemaker JM, et al. The vasovagal response. Clin Sci (Lond) 1991;81(5):575-86.

[3] Bahrami F, Yousefi N. Females are more anxious than males: a metacognitive perspective. Iran J Psychiatry Behav Sci 2011;5(2):83-90.

[4] Lagi A, Cencetti S, Lagi F. Incidence of hypoglycaemia associated with transient loss of consciousness. A retrospective cohort study. Int J Clin Pract 2014;68(8):1029-33.

[5] Lempert T, Bauer M, Schmidt D. Syncope: a videometric analysis of 56 episodes of transient cerebral hypoxia. Ann Neurol 1994;36(2):233-7.

[6] Asadi-Pooya AA, Nikseresht A, Yaghoubi E. Vasovagal syncope treated as epilepsy for 16 years. Iran J Med Sci 2011;36(1):60-2.

[7] Erden I, Yalcin S, Ozhan H. Syncope caused by hyperkalemia during use of a combined therapy with the angiotensin-converting enzyme inhibitor and spironolactone. Kardiol Pol 2010;68(9):1043-6.

[8] Epstein AE, Miles WM, Benditt DG, et al. Personal and public safety issues related to arrhythmias that may affect consciousness: implications for regulation and physician recommendations. A medical / scientific statement from the American Heart Association and the North American 
Society of Pacing and Electrophysiology. Circulation 1996;94(5):1147-66.

[9] Soteriades ES, Evans JC, Larson MG, et al. Incidence and prognosis of syncope. N Engl J Med 2002;347(12):878-85.
[10] Nair N, Padder FA, Kantharia BK. Pathophysiology and management of neurocardiogenic syncope. Am J Managed Care 2003;9(4):327-34.

[11] Kenny RA. Neurally mediated syncope. Clin Geriatr Med 2002;18(2):191-210, vi. 